\title{
Dove e a Desconstrução de Estereótipos: Uma Relação de Simbiose
}

\author{
Bruno Miguel Frutuoso da Costa \\ Faculdade de Letras da Universidade de Coimbra - bruno_frutuoso_costa@hotmail.com
}

\begin{abstract}
Resumo
A publicidade, além de constituir a organização sociocultural de economias de mercado, apresenta-se como um elemento fundamental para a comunicação das marcas. Essa comunicação não se finda na promoção de bens e serviços, como se verifica pela sua capacidade veicular representações sociais, ideais e conceitos estereotipados. A publicidade contemporânea estrutura-se em torno do conceito de Femvertising. $\mathrm{O}$ empoderamento do género feminino e a representação da sua diversidade são apresentados através de desconstruções de estereótipos e do fomento de discussões em torno das várias dimensões da mulher na sociedade. Este estudo pretende analisar à luz da Análise Temática Crítica de Lawless e Chen (2019), a forma como

a Dove integra a desconstrução de estereótipos na campanha publicitária \#MostremNos. Os resultados sugerem que a estratégia se edifica na apresentação de padrões de beleza impostos por diferentes sociedades e na desconstrução das consequências associadas a esses processos históricos, sociais, culturais e económicos na vida de cada menina e mulher. Se, por um lado, a promoção de uma representação mais responsável, inclusiva e diversificada deve ser uma responsabilidade dos media e da publicidade, como é referido nos diversos anúncios, por outro, a Dove apresenta um produto do pós-feminismo que lhe permite manter uma relação de simbiose com altos níveis de popularidade.
\end{abstract}

Palavras-Chave: Dove, publicidade, poder simbólico, estereótipos de género, misoginia.

\section{Dove and the Deconstruction of Stereotypes: A Relationship of Symbiosis}

\begin{abstract}
Advertising is not only the socio-cultural organization of market economies but is also a fundamental element for brands communication. This communication is not limited to the promotion of goods and services, as can be seen by its capacity to promote social representations, ideals and stereotyped concepts. Contemporary advertising is struc-

tured around the concept of Femvertising. The empowerment of the female gender and the representation of its diversity are presented through the deconstruction of stereotypes and the promotion of discussions around the several dimensions of women in society. This study aims to analyse in the light of Lawless and Chen's (2019) Critical Thematic Analysis, how
\end{abstract}




\section{Dove e a Desconstrução de Estereótipos: Uma Relação de Simbiose}

Dove integrates the deconstruction of stereotypes in the advertising campaign \#ShowUs. The results suggest that the strategy is built on the presentation of beauty standards imposed by different societies and the deconstruction of the consequences associated with such historical, social, cultural and economic processes in the life of each girl and woman. If on one side, the promotion of a more responsible, inclusive and diversified representation should be a responsibility of the media and of the advertising, which is referred in the various advertisements, on the other side, Dove presents a product of the post-feminism which allows her maintaining a symbiosis relation with high levels of popularity.

Keywords: Dove, advertising, symbolic power, gender stereotypes, misogyny.

\section{INTRODUÇÃO}

Atualmente, vivemos numa era global e localmente contextualizada por mudanças sociais e políticas cujas desigualdades sociais, económicas, culturais e políticas permitiram o desenvolvimento de novas formas de violência, ódio, misoginia, racismos, xenofobias, fundamentalismos e extremismos que mantêm as mesmas lógicas do passado (Curiel, 2018). Com a sociedade em rede e um meio de comunicação aberto e interativo (Castells, 2006, 2009) rapidamente se assistiu à formação de novos significados através de diversas formas de apropriação (Carlão, Maia, \& Santos, 2017; Silva, Nichel, Martins, \& Borchardt, 2011). A globalização tecnológica, comercial e económica aproximou as pessoas, mas a emergência de redes de comunicações globais e plataforma digitais não estão livres de riscos, uma vez que as relações humanas e respetivas manifestações são complexas (van Mill, 2017).

Se, por um lado, o digital permite o acesso à informação, novas formas de comunicação e formação de identidades individuais (Henry \& Powell, 2014, p. 84), exploração individual da sexualidade (Döring, 2000; Waskul, 2014), atuação e visibilidade do ativismo feminismo (Citron, 2015; Hines, 2019), por outro lado, permitiu a utilização das tecnologias digitais para facilitar comportamentos hostis, perpetuação de agressões sexuais e o surgimento de novas práticas de violência contra mulheres (Henry \& Powell, 2014, 2015, 2018). Investigações demonstram que as vítimas são maioritariamente mulheres e jovens adolescentes (Citron \& Franks, 
2014; Franks, 2016; Hall \& Hearn, 2019) e, nessa direção, impede-se o alcance da justiça e igualdade de género.

Para compreender as formas de violência que se insurgem na atualidade contra as mulheres, torna-se impreterível abarcar práticas de discriminação mais antigas, porque contribuem para a perpetuação do círculo de violência. A discriminação da mulher na sociedade difere consoante o grau de desenvolvimento de cada país, que apresenta uma determinada visão do mundo e do corpo (Le Breton, 2002). Contextos históricos e sociais contribuíram para a produção de saberes, crenças, sentidos e valores sobre os sexos que convergiram na legitimação de divisões sociais baseadas no sexo (Amâncio, 2003, p. 687). Por outras palavras, a cada sexo biológico são atribuídos determinados papeis e comportamentos sociais através de processos de estereotipagem (Hall, 2013). Os estereótipos de género intervêm na construção social e cultural da identidade individual e coletiva do corpo e, portanto, intercedem no imaginário social.

Nesse sentido, a publicidade acaba por refletir as diferenças existentes entre a mulher e o homem na sociedade. Significa que a integração implícita de formas de discriminação em forma de estereótipos de género nos produtos culturais, como é o caso dos anúncios, condiciona as mulheres no alcance da igualdade de oportunidades, ou seja, a igualdade de género (Geis, Brown, Jennings, \& Porter, 1984). Num primeiro momento, Furnham e Mak (1999) demonstraram como a dimensão conservadora portuguesa era intensificada e preservada nos anúncios televisivos. Investigações publicitárias mais recentes demonstram que, embora os estereótipos de género estejam menos acentuados, estes mantêm-se na publicidade portuguesa mesmos após as várias conquistas feministas e com o reposicionamento do papel da mulher na sociedade (Januário, 2016; Pereira \& Veríssimo, 2008; Pereira, Veríssimo, Diaz, \& Correia, 2013). Estes estudos indicam que:

1. Existem dois grupos distintos de enquadramentos da mulher e do homem.

2. A mulher é frequentemente enquadrada em contextos de integração social relacionados com atividades familiares. Os discursos transmitem confiança nas modas emergentes, nomeadamente na escolha, eficácia e qualidade de produtos para a resolução de problemas da esfera privada.

3. O homem surge maioritariamente associado a dimensões sociais simbólicas relacionadas com o prestígio, o estatuto social e atividades de lazer. A presença do ideal de masculinidade "homem ação", o homem produtivo 


\section{Dove e a Desconstrução de Estereótipos: Uma Relação de Simbiose}

e o homem público, que faz, seduz e age, confirmam resquícios de ideais patriarcais e da dominação masculina.

4. Os estereótipos de género estão essencialmente ligados a produtos e respetiva utilização. Enquanto os produtos femininos estão associados à esfera familiar e doméstica, os produtos masculinos relacionam-se com a projeção socioeconómica.

5. O ideal da juventude é um elemento de marginalização de pessoas acima dos 40 anos de idade, vistas como menos produtivas e menos atraentes.

6. A ausência de minorias étnicas sugere a persistência da dominação "branca”.

A publicidade contemporânea que se estrutura em torno do recente conceito de Femvertising procura o empoderamento do género feminino e representação da sua diversidade, quer através de desconstrução de estereótipos e desigualdades de género, quer mediante o fomento de discussões sobre as dimensões das mulheres na sociedade. A Dove, uma das marcas pioneiras, tem conseguido captar a atenção do público feminino para os seus produtos, e desenvolver uma imagem com elevados níveis de popularidade (Nascimento \& Dantas, 2015; Polga \& Silva, 2017).

Nesse sentido, este estudo tem o intuito de analisar criticamente o papel da publicidade e dos processos adotados pela Dove na veiculação de imagens e discursos, que visam a desconstrução e a promoção do rompimento de estereótipos femininos na campanha mais recente da marca. Lançado em 2019 numa parceria conjunta com a Getty Images e a GirlGaze, o projeto \#MostremNos é constituído pela primeira biblioteca de fotografias publicamente acessível para "dar a conhecer as mulheres tal como são" (DOVE, 2019). O corpus de análise é constituído pelos quatro anúncios publicados na página de Youtube da Dove Portugal. A análise qualitativa seguiu o método de Análise Temática Crítica (Lawless \& Chen, 2019) que permite codificar e interpretar discursos através das análises das inter-relações entre os discursos com práticas sociais, relações de poder e ideologias. Por outro lado, a investigação sustenta-se na perspetiva teórica interdisciplinar feminista, onde o género adquire uma maior importância analítica e política para investigar os diferenciais de poder (Curiel, 2018). Doravante, as questões de fundo que norteiam esta investigação são as seguintes:

RQ1: Qual á relação da marca Dove com o conceito publicitário de Femvertising?

RQ2: Como é que os estereótipos de género são desconstruídos na campanha \#MostremNos? 


\section{DISCURSOS DE GÉNERO NA PUBLICIDADE}

A produção de conhecimento sobre a atuação da atividade publicitária é uma preocupação tão antiga quanto a própria prática. Nas palavras de Antonio Caro Almela (2008, p. 81), o conhecimento existente tem insistido na dimensão mais superficial da publicidade enquanto atividade intencionalmente orientada a um público específico com o intuito de alcançar objetivos previamente estabelecidos, e negligenciado a natureza implícita das diferentes finalidades e diversos efeitos sociais, culturais, psicológicos, económicos e institucionais. Segundo Caro (2008), a análise explícita e implícita que carateriza a omnipresença do fenómeno publicitário é intitulada pelo autor de Dispositivo Operacional Publicitário. Inicialmente situado e por definição de forma vertical e interdependente com a Internet emergiu uma revolução comunicacional horizontal e interativa. Nesse sentido, procurámos sintetizar os diversos níveis operacionais da publicidade contemporânea através do Quadro 1.

A publicidade pode desempenhar diferentes identidades e revestir-se de diversas formas consoante os objetivos definidos previamente para as campanhas. Considerada por muitos "a técnica das técnicas" da indústria cultural, esta representa um instrumento de comunicação de marcas e a sua evolução permitiu adquirir técnicas e modelos distintos (Peixoto, 2014). O esforço da publicidade para acompanhar as mudanças sociais peca, na opinião de Carla Cerqueira, por continuar a fazer uso de visões limitadores e estereotipadas sobre questões de género. "Se por vezes parece empoderar os sujeitos/públicos, encerra nos discursos uma visão paradoxal que sedimenta valores culturais tradicionais e a ordem social dominante" (Cerqueira, 2014, p. 8).

Fernando Peixoto preconiza que a publicidade não vende, quanto muito promove, comunica e seduz. Norteia-se pelo princípio do impacto, compreende as dimensões culturais onde se insere, e possui duas caraterísticas essenciais para comunicar e potenciar a mensagem (verbal, não verbal ou mista) de uma forma eficaz com o target $^{1}$ : a sedução e, posteriormente, a assertividade. Enquanto agente sedutor da construção social da realidade, a atividade publicitária desempenha um papel sociocultural importante, nomeadamente ao nível da representação, baseando-se e constituindo-se "não raras vezes" sob a forma de plataformas ideológicas (Peixoto, 2014). Esta visão vai ao encontro da definição de media introduzida por Silveirinha (cit. em Cerqueira,

1 Designação de público-alvo (Peixoto, 2014). 


\section{Quadro 1}

Processos, explícitos e implícitos, e componentes da atividade publicitária a partir dos contributos de Caro (2008, pp. 85-88)

\section{Marco \\ 1. Económico: venda e contratação de produtos e/ou serviços.}

2. Institucional: organismos da administração pública, partidos políticos, associações desportivas, organizações sem fins lucrativos.
Enquanto atividade instrumental, a atuação da publicidade encontra-se situada num marco, assim como o(s) objetivo(s) e os resultados.

Correspondência direta: Anunciantes.

\section{Operativo Semiolinguístico}

Publicitário

1. Estrutura superficial: natureza linguística.

2. Estrutura profunda: natureza semiótica.
Linguagem publicitária expressa-se através de uma construção semiolinguística.

Correspondência direta: Agências de publicidade (departamentos estratégico, criativo, realização e produção).
Comunicação Publicitária

1. Planeamento instrumental.

2. Comunicação mediada.

3. Interação com destinatários ou recetores.
A interação da construção semiolinguística com os recetores da mensagem impulsiona diferentes comportamentos.

Correspondência direta: Meios de comunicação - recetores

\section{Efeitos}

1. Culturais.

2. Sociais.

3. Psicossociais.
Os efeitos estão relacionados com o objetivo publicitário, mas a sua complexidade depende da expansão e relação social.

Correspondência implícita.
Função Ideológica-Institucional

1. Institucional: organização da coesão social.

2. Ideológica: subjacente ao ato de consumo.
A omnipresença da publicidade permite o desenvolvimento de marcas comerciais e corporativas com associação a referências simbólicas. Correspondência implícita.

2014, p.8) como "lugares sociais e políticos de construção de identidades. Por eles perpassam e constroem-se definições e ideologias de diferentes grupos etários, étnicos, de classe, de cultura e de sexo" .

Roland Barthes, pioneiro no campo da semiótica com o desenvolvimento do estudo dos sistemas de signos proveniente da desconstrução da linguística de Saussure, enfatizou a relação do poder com a linguagem, os seus significados e efeitos sociais 
(Barthes, 1964, 2009). O mundo dos significados é o da linguagem, sendo a mesma constituída por signos que só existem se forem reconhecidos, permitindo a sua perpetuação. O problema reside no fato de que "em cada signo dorme este monstro: um estereótipo. Nunca posso falar senão recolhendo aquilo que se arrasta na língua" (Barthes, 2009, p. 15).

Segundo Stuart Hall (2013), a estereotipagem não é mais do que uma prática representacional, um processo de produção de significados que promove a redução das pessoas em torno de caraterísticas simples, essenciais, facilmente e amplamente reconhecidas. Essas caraterísticas desenvolvem-se mediante processos de naturalização, onde se fixa uma diferença marcada pelo exagero e a simplificação. Nesse sentido, os estereótipos apresentam-se como parte estrutural da manutenção da ordem social e simbólica, através das práticas de fechamento e exclusão. Simbolicamente, estabelece-se uma fronteira entre o "normal" e o "outro patológico" (Hall, 2013, pp. 190-192).

O género é fruto de um processo de construção social. As culturas transmitem mensagens sobre o significado de cada sexo, edificando determinados papéis e comportamentos, os estereótipos de género. Essa construção está presente em diversos produtos culturais como leis, educação ou nos discursos veiculados pelos meios de comunicação e pela publicidade. Os estereótipos moldam, portanto, a experiência de cada ser humano e as relações que se estabelecem com o outro (Barker \& Scheele, 2019).

\section{DIVERSOS FEMINISMOS, UM MOVIMENTO SOCIAL FEMINISTA}

A perspetiva teórica e social do feminismo é uma proposta interdisciplinar que nasce do movimento social feminista e da crítica académica. Descodifica estruturas e mecanismos ideológicos e culturais que permitem a reprodução da discriminação e da exclusão de que as mulheres enquanto grupo social são alvo, embora as mesmas análises possam ser utilizadas para compreender outras realidades sociais. O género e a sexualidade passaram a incorporar uma maior importância no campo das ciências sociais como categoria analítica e política a partir do feminismo. Assistiu-se à desnaturalização do que significava ser mulher e à compreensão de que as desigualdades e as hierarquias entre sexos e os papéis de género não eram uma questão natural, mas social e histórica. Por outras palavras, estruturas sociais mais amplas materializam sistemas de representação, por exemplo, de género, raça, etnia, sexualidade e classe 


\section{Dove e a Desconstrução de Estereótipos: Uma Relação de Simbiose}

que são incorporadas e expressas mediante as identidades (Curiel, 2018, pp. 217-220; Garland-Thomson, 2002).

É possível afirmar que existe um movimento social feminista com diferentes tipologias de femininos, correntes feministas, que podem ser enquadradas em três vagas (Januário, 2016, p. 72; Tong, 2009, pp. 46-47):

$1^{\text {a }}$ Vaga, Feminismo Liberal: Génese data os séculos XVIII e XIX e pretendia a eliminação da subordinação e segregação feminina, assim como o alcance da justiça e igualdade de género. Atuava no interior do sistema tendo em vista a mudança de pontos de vista e valores.

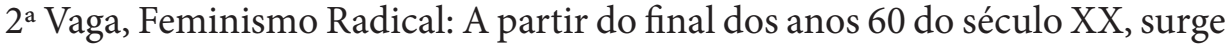
a crítica radical sobre o modelo de feminilidade e de família nuclear na sociedade. Considera que a repressão das mulheres se deve ao sistema vigente em instituições sociais e culturais: o patriarcado. Reivindicava-se um sistema totalmente novo num contexto de modernização marcado pela revolução industrial, o papel dos media e de movimentos sociais, como o feminismo que impulsionou transformações estruturais tradicionais estabelecidas na sociedade ocidental. A mudança de vínculos, valores e crenças culminou no acesso das mulheres ao mercado de trabalho, direito à cidadania e denúncia de formas de dominação masculina.

$3^{\text {a }}$ Vaga, Feminismo Marxista: Relação entre os fundamentos ideológicos marxistas e o feminismo. A partir da década de 90 , preocupação com a divisão do trabalho que mantém as mulheres na esfera privada do lar e os homens no local de trabalho e com a organização económica capitalista.

Desde a década de 70, os estudos de género na publicidade têm ilustrado a tendência da atividade publicitária como uma prática genderizada (Cerqueira, 2014). Destes estudos destaca-se o de Goffman (1987) quando apresentou um estudo pioneiro onde identificava em fotografias de anúncios a forma como os sinais não verbais comunicavam discrepâncias de poder entre homens e mulheres; a objetificação das mulheres e uma representação passiva em relação aos homens. Na opinião de Erving Goffman, a análise das expressões "naturais" de género representadas pelos anúncios publicitários permitia identificar ideias de conceção do sexo feminino e masculino e respetiva relação estrutural. Argumentava que a publicidade influenciava a forma como cada um constrói as suas ideias genderizadas de masculinidade e feminilidade. "Natural expressions are 
commercials performed to sell a version of the world under conditions no less questionable and treacherous than the ones that advertisers face" (Goffman, 1987, p. 84).

O feminismo como movimento social fortalece-se na década de setenta. Embora a partir de distintas correntes, a maioria das feministas concordavam, que aquelas posições que naturalmente tinham sido socialmente atribuídas às mulheres, como mães, esposas, dependentes, não eram naturais, mas antes uma questão cultural e social, ainda que nesta segunda onda, se entendesse que o sexo era algo biológico e o género uma construção social. (Curiel, 2018, p. 222)

Na década de 90, com o surgimento da terceira vaga, a igualdade de género era considerada como um dado adquirido, e sugeria-se que o feminismo poderia ter ido longe de mais à custa dos homens. Investigadoras como Rosalind Gill e Christina Scharff constataram o surgimento de um feminismo instituído na crença de que as mulheres já possuíam poder e direito de escolha. Enquanto sujeitos autónomos, as mulheres praticam a liberdade de escolha sem desigualdades, dado que os padrões anteriores foram "efetivamente" combatidos. Verifica-se, neste sentido, que o pós-feminismo reivindica o empoderamento, mas nega simultaneamente as condicionantes dessa reivindicação (Barker \& Scheele, 2019).

Segundo Soraya Barreto Januário (2016, p. 73), o pós-feminismo enquadra-se para alguns investigadores num feminismo de terceira vaga como resultado do acumular de direitos adquiridos no seio do feminismo da primeira e segunda vagas. Para Januário (2016), as lutas e reivindicações feministas encontram-se atualmente sob a forma de "pós-feminismo". O conceito não deve ser considerado como um marco temporal, mas antes uma reformulação recente de problemáticas e de novas configurações que se insurgem nas relações, outrora reconhecidas socialmente como questões femininas. Ou seja, muitos princípios e direitos femininos conquistados pelas correntes e militâncias feministas mantêm-se ainda no patamar teórico, ainda não são colocados totalmente em prática.

A noção de pós-feminismo tornou-se, por conseguinte, um dos termos mais importantes e contestado no seio das análises culturais feministas. Apesar da ausência de um consenso sobre a sua definição, Rosalind Gill (2007) perspetiva o pós-feminismo como uma nova sensibilidade, onde coexiste a representação de discursos feministas e antifeministas, cujo objeto é a cultura mediática e a relação do feminismo com ideologias neoliberais. 
Os estudos desenvolvidos por Gill $(2003,2007,2008)$ permitem compreender as modificações ocorridas no campo da representação mediática feminina com o surgimento da terceira vaga do feminismo. Inicialmente, a noção de feminilidade demonstrou uma cultura mediática obcecada com a definição e escrutínio de ideais dos corpos das mulheres tendo como base corpos de celebridades (Gill, 2007). Assistiu-se à transição da objetivação sexual das mulheres para uma subjetificação sexual. A representação objetificada do corpo das mulheres e a celebração do sucesso e do poder do género feminino desencadearam a construção da nova feminilidade contemporânea estruturada na confiança sexual ${ }^{2}$ e na autonomia ${ }^{3}$ (Gill, 2003). Gill (2008) identificou ainda três tendências nos discursos de empoderamento feminino na publicidade contemporânea: mulher como figura da heterossexualidade ativa, mulher vingativa e a "lésbica boazona". De objetos passivos ao olhar masculino, pouco cultas, desprovidas de conteúdo, as jovens mulheres passaram a ser retratadas como ativas, bonitas, inteligentes, independentes e sexualmente poderosas (Gill, 2008, pp. 52-55).

Numa entrevista dada em 2017, Rosalind Gill considera notável o esforço dos media em responder ao ativismo e visibilidade de movimentos trans, dos géneros queer e das sexualidades. Os vários estudos desenvolvidos pela autora permitiram-lhe compreender que os meios de comunicação e a publicidade utilizam os ideias feministas de uma forma seletiva, ao construírem novas figuras, como a mulher empoderada, sexualmente desejável e pós-feminista. Muitas das figuras construídas confrontam o patriarcado, a heteronormatividade ou o capitalismo. No entanto, sublinha que a aparência do corpo feminino está cada vez mais tóxica e as novas alfabetizações do padrão de feminilidade direcionam-se ao ínfimo detalhe das imperfeições. Para Gill, os sinais de esperança são percetíveis, mas os sinais de injustiça continuam presentes e deve-se em certa medida à coexistência do feminismo com o antifeminismo. Destaca-se a luta contínua por representações mais igualitárias e justas das mulheres, onde o pós-feminismo continua a adotar a perspetiva crítica necessária para estabelecer mudanças sociais (Matos, 2017).

2 Sujeitos sexuais conhecedores, ativos e desejosos (Gill, 2003).

3 "A jovem sexual, heterossexual, autónoma, que brinca com o seu poder sexual e está sempre à altura" (Gill, 2003, p. 103). Indica uma objetificação sexual mais refinada. Representa apenas algumas mulheres e exclui outras tantas. 


\section{A PUBLICIDADE POLITICAMENTE CORRETA, UMA RELAÇÃO DE SIMBIOSE}

Em 1984, Geis et al. já constatavam que a exposição de mulheres ao reverso de papéis estereotipados em anúncios poderia modificar a conceção social subentendida que remetia a mulher à esfera privada do lar e mantinham-na afastada das igualdades de oportunidades, nomeadamente ao nível das carreiras profissionais. A mudança iniciava-se na presença de estímulos e de mensagens implícitas de que as mulheres poderiam ser autónomas e importantes cada uma à sua maneira.

Uma grande percentagem da publicidade contemporânea estrutura-se em discursos politicamente corretos sobre temáticas relacionadas com desigualdades de género. Esta estratégia tem permitido que marcas desconstruam estereótipos e fomentem discussões sobre a temática. Conseguem captar a atenção principalmente do público feminino e materializam-na com elevados níveis de popularidade. Nesse sentido, a tendência atual da atividade publicitária é orientada em função do conceito Femvertising, no empoderamento do género feminino e na representação da sua diversidade, através da desconstrução de estereótipos e do fomento de discussões sobre as várias dimensões da mulher na sociedade (Nascimento \& Dantas, 2015; Polga \& Silva, 2017).

Uma análise pormenorizada de Femvertising permite identificar a união do movimento feminista e respetivos ideais - Feminism - à publicidade - advertising. No decorrer da 11 a edição da Advertising Week ${ }^{4}$, em 2014, a diretora executiva da SheKnows, Samantha Skey, promoveu um debate em torno do papel da indústria da comunicação na veiculação e perpetuação de estereótipos negativos, e a forma como a publicidade começou a desencadear um movimento em torno do empoderamento feminino. O debate permitiu alertar para o facto de as marcas terem identificado que o público feminino já não se identificava mais com as mensagens veiculadas. Como sentiram a necessidade de demonstrarem um novo posicionamento em relação às mulheres, procederam à incorporação do feminismo no discurso publicitário. A partir de 2015, assistiu-se a um movimento publicitário em torno do conceito e abordam fundamentalmente temas como a liberdade, igualdade, beleza, maternidade, casa-

4 Evento de publicidade internacional de grande notoriedade. Reúne milhares de participantes anualmente desde a sua criação, em 2004, na cidade de Nova Iorque. Durante uma semana, profissionais de renome participam em palestras e mesas redondas para abordar o poder da publicidade, das indústrias coexistentes e envolver os mais jovens no empreendedorismo do meio publicitário (Nascimento \& Dantas, 2015). 
mento, desconstrução e rompimento de estereótipos (Nascimento \& Dantas, 2015; Polga \& Silva, 2017).

A Dove, pertencente ao grupo Unilever, está presente em mais de oitenta países e atua no setor da higiene pessoal e beleza. Há dezasseis anos, desencadeou um processo de reposicionamento da sua imagem com o lançamento da campanha Beleza Real. No Brasil, a campanha atingiu visualizações na ordem dos sete milhões. Por um lado, este fenómeno deve-se à reestruturação do posicionamento da marca que se apresentou mais inclusiva, ao alargar o seu público-alvo para as classes sociais B e C. Por outro, a campanha descodificava uma padronização excessiva e a impossibilidade de se alcançar a beleza perfeita. Introduziu uma visão mais saudável e democrática sobre a beleza feminina, questionou os padrões de beleza impostos pela sociedade e desconstruiu estereótipos em torno do género feminino. Os discursos veiculados sublinhavam a existência de uma diversidade de belezas reais femininas, propondo às mulheres uma visão menos crítica de si mesmas, uma aceitação de como são, porque cada mulher é maravilhosa à sua maneira. Uma ampla discussão foi desencadeada, a notoriedade da Dove cresceu vertiginosamente colocando-a num patamar de destaque, o que desencadeou muitas investigações académicas sobre esta campanha (Ramalho, Amaral, Calvi, Ulbrich, \& Kulack, 2016; Polga \& Silva, 2017).

\section{OBJETIVOS E CAMINHOS METODOLÓGICOS}

Este estudo pretende analisar criticamente o papel da publicidade, nomeadamente os processos adotados pela Dove na veiculação de imagens e discursos que visam a desconstrução de estereótipos e, posteriormente, o seu rompimento na campanha publicitária mais recente da marca. Divulgado em 2019 numa parceria conjunta com a Getty Images ${ }^{5}$ e a GirlGaze ${ }^{6}$, o projeto \#MostremNos é constituído pela primeira biblioteca de fotografias publicamente acessível com o intuito de desconstruir os estereótipos de beleza a nível mundial e "dar a conhecer as mulheres tal como são" (DOVE, 2019).

5 Getty Images é uma das principais e mais reconhecidas empresas a nível mundial no que diz respeito à criação e distribuição de imagens (DOVE, 2019).

6 GirlGaze é uma comunidade global de fotógrafas "que estão a mudar o modo como as mulheres são vistas" (DOVE, 2019). 
No website ${ }^{7}$ oficial do projeto constata-se que o principal motivo da sua génese se prende com o facto de $70 \%$ das mulheres ainda não se sentirem representadas na publicidade e nos meios de comunicação. Nesse sentido, apresentam um espaço com 5000 imagens de mulheres, fotografadas por mulheres e indivíduos não binários que se identificam como mulheres. Patenteiam e alvitram à própria indústria criativa uma visão mais ampla de beleza, e uma redefinição da representação mediática atual das mulheres (DOVE, 2019).

A partir das teorias de Foucault (1994a, 1994b, 1994c) considera-se que é necessário impulsionar a escrita de uma nova história da sexualidade. Para tal, é necessário fomentar um olhar crítico sobre o pensamento social vigente e historicamente construído de repressões e condicionalismos históricos sobre as mulheres. Durante vários séculos, os comportamentos sociais das mulheres foram reprimidos e as normas sociais vigentes contribuíam para a sua objetificação. "As fiéis guardiãs do lar" cuidavam da esfera privada doméstica em sociedades dominadas pelos homens (Bourdieu, 2012). Ressalta-se que a dominação masculina como ocorre no terreno das trocas simbólicas é, nesse sentido, uma violência simbólica muitas vezes exercida de forma invisível. Socorre-se de instrumentos simbólicos de comunicação, de conhecimento e de construção social da realidade, onde se inserem os media e a publicidade, e perpetuada por instituições como o Estado, a Escola e Igreja (Bourdieu, 1989, 2012).

\section{Tabela 1}

Constituição do corpus de análise

\begin{tabular}{|c|c|c|c|}
\hline Designação & Duração & Link & Publicação \\
\hline Dove | \#MostremNos (1) & 15 segundos & $\begin{array}{l}\text { https://www.youtube.com/ } \\
\text { watch?v=2keDbZaFOzM }\end{array}$ & $06 / 06 / 2019$ \\
\hline $\begin{array}{l}\text { Dove |\#MostremNos - Be- } \\
\text { hind the Scenes ( } 2 \text { ) }\end{array}$ & $\begin{array}{l}1 \text { minuto e } 47 \\
\text { segundos }\end{array}$ & $\begin{array}{l}\text { https://www.youtube.com/ } \\
\text { watch?v=XHjbRiVoUQc }\end{array}$ & $10 / 05 / 2019$ \\
\hline Dove |\#MostremNos (3) & 30 segundos & $\begin{array}{l}\text { https://www.youtube.com/ } \\
\text { watch?v=YIc9MtNQxj4 }\end{array}$ & 09/05/2019 \\
\hline Dove |\#MostremNos (4) & $\begin{array}{c}2 \text { minutos e } 8 \\
\text { segundos }\end{array}$ & $\begin{array}{l}\text { https://www.youtube.com/ } \\
\text { watch?v=VXbewr1YDDY }\end{array}$ & $26 / 04 / 2019$ \\
\hline
\end{tabular}

7 Vide https://www.dove.com/pt/stories/campaigns/mostremnos.html. Consultado a 5 de abril de 2020. 
O corpus de análise, demonstrado na tabela 1, é constituído pelos quatro anúncios do projeto publicados na página de Youtube Dove Portugal, porque é importante a realização de análises e investigações que incorporem outros media como a Internet, dado que "a contemporaneidade permite uma constante e crescente rutura de paradigmas sociais” (Januário, 2016, p. 352).

A análise qualitativa seguiu o método da Análise Temática Crítica, desenvolvida por Lawless e Chen (2019), que permite codificar e interpretar discursos através das análises das inter-relações entre os discursos com práticas sociais, relações de poder e ideologias. As experiências partilhadas nos discursos permitem identificar padrões que se encontram vinculados a hegemonias e ideologias maiores. Torna-se possível abordar e desenvolver temas criticamente que são provenientes de um conjunto de subtemas de um primeiro momento de codificação. Por outro lado, a investigação sustenta-se na perspetiva teórica interdisciplinar feminista, onde o género adquire uma maior importância analítica e política para investigar os diferenciais de poder (Curiel, 2018). Nesse sentido, as questões de fundo que norteiam esta investigação são as seguintes:

RQ1: Qual á relação da marca Dove com o conceito publicitário de Femvertising?

RQ2: Como é que os estereótipos de género são desconstruídos na campanha \#MostremNos?

\section{RESULTADOS E DISCUSSÃO}

A codificação foi dividida em duas fases distintas. Primeiro, seguiu-se os critérios da Análise Temática de Owen (cit. em Lawless \& Chen, 2019, p. 103) para identificar padrões de discursos recorrentes, repetidos e/ou vigorosos. Esta etapa de codificação aberta permitiu identificar temas emergentes dos padrões discursivos. De seguida, realizou-se o processo de codificação fechada (Lawless \& Chen, 2019, p. 100) dos discursos dos anúncios ao questionar aos temas emergentes de que forma se interligavam entre as diferentes alocuções e com ideologias sociais mais amplas. Nesta etapa final, produziram-se dois temas críticos mais amplos a partir de onze subtemas críticos, que articulam ideologias, posições de poder e hierarquias de status como mostra o Esquema 1. 


\section{Esquema 1}

Temas e subtemas críticos
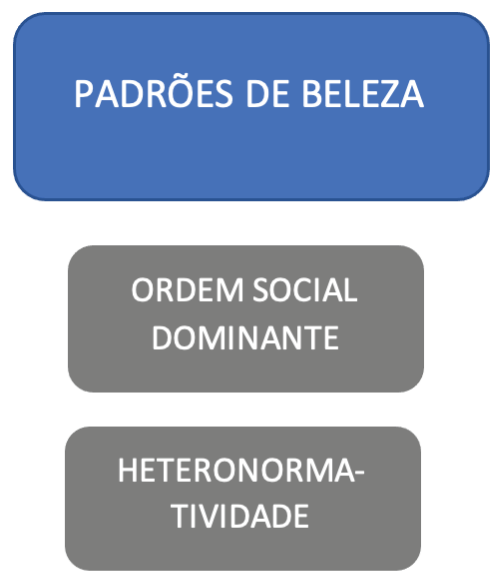

NOVAS

ALFABETIZAÇÕES

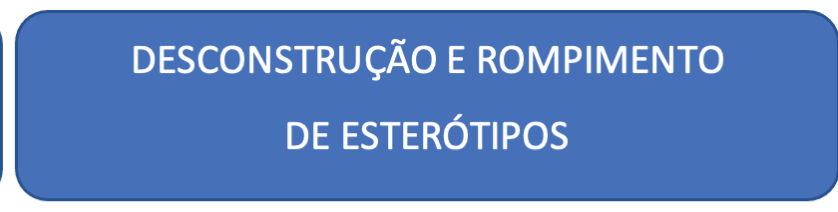

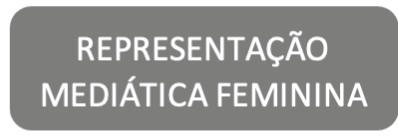

ESTEREÓTIPOS DE BELEZA

INCLUSÃO

MUDANÇAS SOCIAIS
TRATAMENTO

DIFERENCIAL

ESTEREÓTIPOS DE

GÉNERO

COMUNIDADE LGBTQ+

EMPODERAMENTO

FEMININO

\section{Temas utilizados para uma abordagem dos padrões de beleza}

Grande parte das imagens e situações retratadas são transversais aos quatro anúncios da Dove sobre o projeto \#MostremNos. A diferença reside no grau de desenvolvimento consoante a duração de cada vídeo publicitário. O primeiro tema crítico - padrões de beleza - é observado com maior intensidade nas imagens do que nos discursos veiculados pelos quatro anúncios (Goffman, 1987). Fazem referência para a existência de uma ordem social dominante (Cerqueira, 2014) edificada em padrões ocidentais na definição de beleza feminina: mulher branca, jovem, ocidental, heterossexual, maquilhada e sem imperfeições (acne e sardas), cabelo arranjado e vistoso, unhas de gel, sensual, esbelta e apresenta um corpo tonificado (Gill, 2003, 2007, 2008; Januário, 2016; Matos, 2017).

A Dove enfatiza que "não podemos ser aquilo que não vemos", sendo que a sociedade está constantemente a incutir nas mulheres e raparigas de todo o mundo como devem ser e agir (Bourdieu, 1989). Salienta que a representação mediática feminina impõe padrões de beleza em todas as culturas (Caro, 2008; Januário, 2016; Peixoto, 
2014; Pereira \& Veríssimo, 2008; Pereira et al., 2013), e como essa preocupação começa na infância e percorre a vida toda. Representa-se uma diversidade de situações que demonstram mulheres e raparigas infelizes e constrangidas com o que exigem das mesmas.

Uma das situações representadas demonstra uma mulher de mãos dadas com uma criança, que aparenta ter cerca de seis anos, rodeadas de pessoas numa rua movimentada, a olharem fixamente e com um ar apreensivo para uma publicidade dos quatro outdoors de um centro comercial. Os outdoors apresentam e contribuem para a validação dos padrões de beleza impostos pela sociedade contemporânea que se insere num contexto heteronormativo e capitalista (Matos, 2017). O que as mulheres e raparigas veem molda e influencia a visão que cada tem sobre o mundo e como interagem com o outro. Quem não seguir as condutas socialmente válidas ficará em desvantagem perante o resto da sociedade, e, poderá ser alvo de argumentos discriminatórios e preconceituosos (Barker \& Scheele, 2019; Cerqueira, 2014; Hall, 2013).

Três outdoors desse centro comercial fazem referência ao uso de maquilhagem, sugerindo que todas as mulheres devem ser bonitas, ao esconder as imperfeições e manchas indesejáveis do rosto, como a acne, sardas e problemas de pele. Todos apresentam mulheres em poses sensuais, elegantes, esbeltas, corpos tonificados e utilizam unhas de gel. Aquele que capta a atenção da mulher e da criança representa um objetificação sensual de uma modelo, deitada num barco no meio do oceano, a publicitar o uso de um biquíni, e, portanto, o contexto heteronormativo está ainda presente e visível. Por outro lado, características que se prendem com o facto de ser-se morena, ter cabelos lisos, olhos castanhos, corpo esbelto, tonificado e sem tatuagens, piercings e imperfeições remetem para as novas alfabetizações de um padrão de feminilidade que se direciona para o ínfimo detalhe das imperfeições (Matos, 2017).

\section{Temas implementados na desconstrução e rompimento de estereótipos}

O segundo tema crítico identificado - desconstrução e rompimento de estereótipos - encontra-se presente de igual forma nos discursos e nas imagens veiculadas. $\mathrm{O}$ principal objetivo da Dove é desconstruir e romper com os estereótipos de beleza e de género na representação mediática de mulheres e raparigas (Nascimento \& Dantas, 2015; Polga \& Silva, 2017). O discurso mais enfatizado no início de cada anúncio é 
o de que "70\% das mulheres ainda não se vêem representadas nos meios de comunicação e na publicidade". A marca sinaliza constantemente esta preocupação. Mostra que está ao lado das mulheres de todo o mundo e que vai continuar a adotar uma voz ativa nesta luta, uma luta pós-feminista.

Nesse sentido, apresenta uma solução encontrada pela marca para impulsionar mudanças sociais nos meios de comunicação e na publicidade: "Dove e mulheres de todo o mundo estão a construir a maior biblioteca de fotografias de sempre para acabar com os estereótipos de beleza, disponível para todos os meios de comunicação e publicidade" (Dove, 2019). Promove um processo de consciencialização do ramo que se apresenta como o principal agente de construção social da realidade (Bourdieu, 1989; Caro, 2008; Peixoto, 2014): "como profissionais de imagem, temos a responsabilidade de refletir a sociedade de uma forma autêntica e ajudar a fomentar uma mudança social", ao apresentar uma "visão muito mais ampla de como as mulheres são em todas as partes do mundo. Mostrem-nos um mundo onde todas as mulheres e raparigas se sintam vistas e representadas" (Dove, 2019).

A marca pretende demonstrar que a diversidade cultural é uma riqueza da humanidade, que somos todos iguais e onde a cultura deve ser respeitada. Reconstrói determinadas situações, histórias e apresenta testemunhos de mulheres, conferindo-lhes voz para demonstrar que existem estereótipos de género e padrões de beleza que são definidos por uma ordem social dominante, com novas alfabetizações, num contexto ainda heteronormativo, com consequências diretas na vida das mulheres de todo o mundo (Amâncio, 2003; Barker \& Scheele, 2019; Cerqueira, 2014; Gill, 2003, 2007, 2008). As estratégias discursivas subentendem e pretendem transmitir o empoderamento do género feminino através da seleção de alguns ideais do movimento feminista (Matos, 2017).

És tão nova, mas vês tudo. Não podemos ser aquilo que não vemos. E se te pudéssemos mostrar uma visão de beleza, onde nenhuma rapariga ou mulher se sentisse excluída? Onde todos os tipos de pele sejam bonitos. Onde nos mostrassem exatamente da mesma forma que a todas outras. Onde a feminilidade seja força. Onde a beleza seja não binária. Porque se te mostrarmos um mundo onde todas as mulheres são realmente vistas, então tu vais mostrar-nos a realidade. (Dove, 26 abril de 2019) 
Ao utilizar várias vezes a expressão "e se" deixa no ar a incógnita se é mesmo possível desencadear uma mudança social eficaz e reverter a situação atual. As mulheres identificam um tratamento diferencial por não se enquadrarem nos padrões impostos pela sociedade. Através de fotos, testemunhos, recriação de situações e a utilização de voz off, a Dove apresenta uma definição de beleza tangível mais inclusiva e quebra a padronização excessiva. Os anúncios representam uma diversidade de mulheres que se orgulham de ser como são, nomeadamente mulheres que não seguem os padrões de beleza e de género e que por norma não são representadas nos media. As mulheres querem sentir-se representadas e sem qualquer tipo de constrangimento: "Mostrem-nos mais mulheres como eu", "mostrem-nos que o bem-estar não depende do tamanho", "mostrem-nos que todos os cabelos são profissionais", "mostrem-nos!". Para além de desconstruir os estereótipos de beleza, a marca também rompe com outras formas de discriminação ao representar a diversidades de orientações sexuais através da comunidade LGBTQ+.

Elle Rose, defensora dos Direitos Transgénero, África do Sul: “Eu acho muito importante que haja pelo menos uma criança que se reveja em mim. As pessoas têm a ideia de que tens de ser corajosa para seres quem és".

Fotógrafa do projeto \#MostremNos, de Mumbai, Índia: "Num país como a Índia, se fores gay ou bissexual, as pessoas vão imediatamente julgar-te. Mas a Monisha não se importa”.

Fotógrafa do projeto \#MostremNos, de Marraquexe, Marrocos: "Se eu conseguir quebrar o estereótipo e mudá-lo com uma fotografia de cada vez, então vou fazê-lo até poder".

\section{CONSIDERAÇÕES FINAIS}

Este estudo permite demonstrar as linhas gerais do caminho trilhado pelo movimento feminista e o seu estágio atual. O pós-feminismo veio demonstrar, e criticar ao mesmo tempo, que a igualdade de género não é e nunca poderá ser considerada como um dado adquirido como se reivindica a partir da terceira vaga feminista. Significa que as lutas e reivindicações feministas encontram-se atualmente sob a forma de "pós-feminismo". Ou seja, a reformulação de problemáticas e de novas configurações que se insurgem nas relações, outrora reconhecidas socialmente como questões femininas, deve-se ao facto de vários princípios e direitos femininos conquistados 
anteriormente mantêm-se ainda apenas no patamar teórico (Januário, 2016). A título exemplificativo, esta realidade tem sido demonstrada em diversos estudos como os de Rosalind Gill (2003, 2007, 2008).

Verificam-se várias mudanças positivas acerca da representação feminina nos discursos mediáticos, mas essas mudanças estão longe de alcançar o patamar desejável e, portanto, continuam a suscitar desafios. A Internet permitiu um crescimento da atuação e da visibilidade dos feminismos (Citron, 2015; Hines, 2019). A partir de um meio aberto e interativo (Castells, 2006, 2009), surgiram novas formas de reivindicação e de partilha de histórias, ideias, preocupações, revoltas e agressões de que as mulheres são alvo a um nível expressivo (Citron \& Franks, 2014; Franks, 2016; Hall \& Hearn, 2019).

As marcas iniciaram um processo de conscientização sobre a deficitária e estereotipada representação mediática das mulheres nos media e na publicidade. Os ganhos associados a processos de reposicionamento têm levado várias marcas de produtos íntimos e de beleza, neste caso em particular a Dove, a uma integração do conceito de Femvertising nos discursos publicitários. O empoderamento do género feminino, a representação da sua diversidade através de desconstrução de estereótipos, e o fomento de discussões relativamente às várias dimensões da mulher na sociedade são algumas estratégias adotadas pelas marcas (Nascimento \& Dantas, 2015; Polga \& Silva, 2017).

Os anúncios do projeto \#MostremNos demonstram o propósito do empoderamento feminino. As estratégias discursivas adotadas refletem uma desconstrução de estereótipos e dos padrões de beleza impostos por uma ordem social dominante, com novas alfabetizações, num contexto com resquícios da heteronormatividade, e muitas vezes exercida por uma violência simbólica (Bourdieu, 1989, 2012). A construção dos anúncios com base na recriação de situações e histórias, verídicas ou apenas exemplificativas, e apresentação de testemunhos permitem que as mulheres tenham voz ativa, na denúncia dos constrangimentos e dos impactos resultantes de uma representação mediática desigualitária. Por outro lado, nota-se uma preocupação em apresentar-se como uma marca inclusiva e, portanto, representa a diversidade de orientações sexuais e a comunidade LGBT+. Nesse sentido, a Dove assume-se como porta-voz de todas as mulheres que desejam diversas mudanças sociais, muitas delas já conquistadas na primeira e segunda vagas somente para o patamar teórico (Januário, 2016).

Resumindo, toda e qualquer forma de discriminação é atualmente menos representada na publicidade do que outrora (Pereira \& Veríssimo, 2008; Pereira et al., 


\section{Dove e a Desconstrução de Estereótipos: Uma Relação de Simbiose}

2013). No entanto, enquanto houver representações sociais estereotipadas na indústria criativa, as mesmas estão a contribuir para a discriminação da mulher na sociedade e a perpetuação de um círculo de violência que hoje assume contornos preocupantes no digital (Henry \& Powell, 2014, 2015, 2018). As mensagens publicitárias em torno do conceito de Femvertising não são mais do que o pós-feminismo em ação ao utilizarem discursos pós-feministas, que incorporam e repudiam simultaneamente os ideiais feministas e, nesse seguimento, contribuem para o aniquilamento da força política do feminismo (Gill, 2003, 2007, 2008; Matos, 2017). Marcas como a Dove apresentam objetos de consumo, ou seja, vendem o feminismo quando este não pode ser vendido ou comprado. A despolitização e a desarticulação do movimento feminista têm de ser repensadas com o objetivo primordial de desencadear mudanças sociais efetivas numa sociedade cada vez mais desafiante.

\section{REFERÈNCIAS}

Amâncio, L. (2003). O género no discurso das ciências sociais. Análise Social, 168, 687-714. http://hdl.handle.net/10071/18123

Barker, M., \& Scheele, J. (2019). Gender: a graphic guide. London: Icon Books.

Barthes, R. (2009). Aula (L. Perrone-Moisés, Trad.). São Paulo: Editora Cultrix. (Trabalho publicado pela primeira vez em 1977).

Barthes, R. (1964). Elementos de Semiologia (I. Blikstein, Trad.). São Paulo: Editora Cultrix.

Bourdieu, P. (1989). O poder simbólico (F. Tomaz, Trad.). Difel Difusão Editorial.

Bourdieu, P. (2012). A dominação masculina (M. Kühner, Trad.). Rio de Janeiro: Bertrand Brasil. (Trabalho publicado pela primeira vez em 1998).

Carlão, A., Maia, C., \& Santos, M. (2017). Deliberação nos comentários dos leitores de jornais online: Caso da secção de educação do público.pt. Internet Latent Corpus Journal, 7(1), 5-27. https://proa.ua.pt/index.php/ilcj/article/view/571/466

Caro, A. (2008). La publicidad como dispositivo operacional. Pensar la Publicidad Revista Internacional De Investigaciones Publicitarias, 2(2), 81-106. https:// revistas.ucm.es/index.php/PEPU/article/view/PEPU0808220081A 
Castells, M. (2006). A sociedade em rede: Do conhecimento à política. Em M. Castells \& G. Cardoso (Eds.), A sociedade em rede: Do conhecimento à ação política (pp. 17-30). Imprensa Nacional da Casa da Moeda.

Castells, M. (2009). Comunicação e poder (M. Hernández, Trad.). Alianza Editorial.

Cerqueira, C. (2014). Os média, os públicos e os discursos de género: (in)visibilidades, linguagens e protagonistas. Em A. Jorge, C. Cerqueira \& S. Magalhães (Eds.), PubliDiversidade. Representações Sociais e Igualdade de Género na Publicidade (pp. 7-16). https://issuu.com/publidiversidade/docs/publidiversidade

Citron, D. K., \& Franks, M. A. (2014). Criminalizing revenge porn. Wake Forest Law Review, 49, 345-391. https://repository.law.miami.edu/cgi/viewcontent. cgi? article $=1059 \&$ context $=$ fac_articles

Citron, D. K. (2015). Addressing cyber harassment: An overview of hate crimes in cyberspace. Journal of Law, Technology \& the Internet, 6, 1-12. https:// scholarlycommons.law.case.edu/jolti/vol6/iss $1 / 3$

Curiel, O. (2018). Género, raça, sexualidade - debates contemporâneos. Em M. Baptista (Ed.), Género e performance: Textos essenciais vol. I (pp. 215-238). Coimbra: Grácio Editor. (Trabalho publicado pela primeira vez em 2005).

Döring, N. (2000). Feminist views of cybersex: Victimization, liberation, and empowerment. Cyber Psychology \& Behavior, 3(5), 863-884. https://doi. org/10.1089/10949310050191845

DOVE. (2019). Projeto \#MostremNos. Disponível a 2 maio 2020 em https://www. dove.com/pt/stories/campaigns/mostremnos.html

Franks, M. A. (2016, 22 setembro). Drafting an effective "Revenge Porn" law: A guide for legislators. Cyber Civil Rights Initiative. Disponível a 10 dez. 2020 em https:// www.cybercivilrights.org/guide-to-legislation/

Foucault, M. (1994a). História da sexualidade I: A vontade de saber (P. Tamen, Trad.). Relógio D’Água. (Trabalho publicado pela primeira vez em 1976).

Foucault, M. (1994b). História da sexualidade II: O uso dos prazeres (M. Alberto, Trad.). Relógio D’Água. (Trabalho publicado pela primeira vez em 1984). 
Foucault, M. (1994c). História da sexualidade III: O cuidado de si (M. Alberto, Trad.). Relógio D’Água. (Trabalho publicado pela primeira vez em 1984).

Furnham, A., \& Mak, T. (1999). Sex-role stereotyping in television commercials: A review and comparison of fourteen studies done on five continents over 25 years. Sex Roles, 41(516), 413-436. https://doi.org/10.1023/A:1018826900972

Garland-Thomson, R. (2002). Integrating disability, transforming feminist theory. NWSA Journal, 14(3), 1-32. http://www.jstor.org/stable/4316922

Geis, F. L., Brown, V., Jennings, J., \& Porter, N. (1984). TV commercials as achievement scripts for women. Sex Roles, 10(7/8), 513-525. https://doi.org/10.1007/ BF00287260

Gill, R. (2003). From Sexual Objectification to Sexual Subjectification: The Resexualisation of Women's Bodies in the Media. Feminist Media Studies, 3(1), 100-106. https://doi.org/10.1080/1468077032000080158

Gill, R. (2007). Postfeminist media culture: Elements of a sensibility. European Journal of Cultural Studies, 10(2), 147-166. https://doi.org/10.1177/1367549407075898

Gill, R. (2008). Empowerment/Sexism: Figuring Female Sexual Agency in Contemporary Advertising. Feminism \& Psychology, 18(1), 35-60. https://doi. org/10.1177/0959353507084950

Goffman, E. (1987). Gender advertisements. New York: Harper \& Row Publishers.

Hall, M., \& Hearn, J. (2019). Revenge pornography and manhood acts: A discourse analysis of perpetrators' accounts. Journal of Gender Studies, 28(2), 158-170. https://doi.org/10.1080/09589236.2017.1417117

Hall, S. (2013). O espetáculo do “outro". Em S. Hall, Cultura e Representação (pp. 139231). Editorial: Apicuri.

Henry, N., \& Powell, A. (2014). The dark side of the virtual world: Towards a digital sexual ethics. Em N. Henry \& A. Powell (Eds.), Preventing sexual violence: Interdisciplinary approaches to overcoming a rape culture (pp. 84-104). Palgrave Macmillan. https://doi.org/10.1057/9781137356192_5 
Henry, N., \& Powell, A. (2015). Embodied harms: Gender, shame, and technologyfacilitated sexual violence. Violence Against Women, 21(6), 758-779. https://doi. org/10.1177/1077801215576581

Henry, N., \& Powell, A. (2018). Technology-facilitated sexual violence: A literature review of empirical research. Trauma, Violence, \& Abuse, 19(2), 195-208. https:// doi.org/10.1177/1524838016650189

Hines, S. (2019). The feminist frontier: On trans and feminism. Journal of Gender Studies, 28(2), 145-157. https://doi.org/10.1080/09589236.2017.1411791

Januário, S. B. (2016). Masculinidades em (re)construção: Género, corpo e publicidade. Covilhã: LabCom.

Lawless, B., \& Chen, Y. (2019). Developing a Method of Critical Thematic Analysis for Qualitative Communication Inquiry. Howard Journal of Communications, 30(1), 92-106. https://doi.org/10.1080/10646175.2018.1439423

Le Breton, D. (2002). Antropologia del cuerpo y modernidad (P. Mahler, Trad.). Buenos Aires: Ediciones Nueva Visión. (Trabalho publicado pela primeira vez em 1990).

Matos, C. (2017). Rosalind Gill: "We don't just want more cake, we want the whole bakery!”. MATRIZes, 11(2), 137-160. https://doi.org/10.11606/issn.1982-8160. v11i2p137-160

Nascimento, M. C., \& Dantas, J. B. (2015). O Femvertising em evidência: Estudo de caso \#Likeagirl. Intercom - Sociedade Brasileira de Estudos Interdisciplinares da Comunicação. XXXVIII Congresso Brasileiro de Ciências da Comunicação Rio de Janeiro. http://portalintercom.org.br/anais/nacional2015/resumos/R101779-1.pdf

Peixoto, F. (2014). Publicidade, Sedução e Assertividade: A Comunicação de Marca, Hoje. Em Comunicação Global, Cultura e Tecnologia: livro de atas $8^{\circ}$ Congresso SOPCOM, 856-864. ISBN: 978-989-20-3877-3

Pereira, F. C., \& Veríssimo, J. (2008). A mulher na publicidade e os estereótipos de género. Observatorio $\left(\mathrm{OBS}^{*}\right)$ Journal, 2(2), 281-296. http://obs.obercom.pt/ index.php/obs/article/view/120 


\section{Dove e a Desconstrução de Estereótipos: Uma Relação de Simbiose}

Pereira, F. C., Veríssimo, J., Diaz, A. C., \& Correia, R. (2013). Estereótipos de género, sexo e violência na publicidade portuguesa e espanhola. Comunicação e Sociedade, 23, 254-273. https://doi.org/10.17231/comsoc.23(2013).1625

Polga, G. H., \& Silva, I. A. (2017). Femvertising: empoderamento feminino na publicidade contemporânea. Intercom - Sociedade Brasileira de Estudos Interdisciplinares da Comunicação. XXII Congresso de Ciências da Comunicação na Região Sul - Caxias do Sul - RS. https://portalintercom.org. br/anais/sul2017/resumos/R55-1437-1.pdf

Ramalho, E., Amaral, A. R., Calvi, D. R., Ulbrich, T. H., \& Hulack, S. M. (2016). Dove e seu posicionamento: Um estudo sobre a importância do simbolismo como estratégia de comunicação. Em O Empoderamento do Indivíduo: Anais do $14^{\circ}$ Encontro Científico Cultural Interinstitucional, 1-5. ISSN: 1980-7406

Silva, R. L., Nichel, A., Martins, A. C., \& Borchardt, C. K. (2011). Discursos de ódio em redes sociais: Jurisprudência brasileira. Revista Direito GV, 7(2), 445-467. https://doi.org/10.1590/S1808-24322011000200004

Tong, R. (2009). Feminist thought: A more comprehensive introduction. Colorado: Westview Press.

van Mill, D. (2017, 1 maio). Freedom of speech. The Standford Encyclopedia of Philosophy. Disponível a 16 nov. 2020 em https://plato.stanford.edu/entries/ freedom-speech/

Waskul, D. D. (2014). Techno-sexuality: The sexual pragmatists of the technological age. Em T. Weinberg \& S. Staci (Eds.), Selves, symbols, and sexualities: An interactionist anthology (pp. 89-107). Sage Publications. 